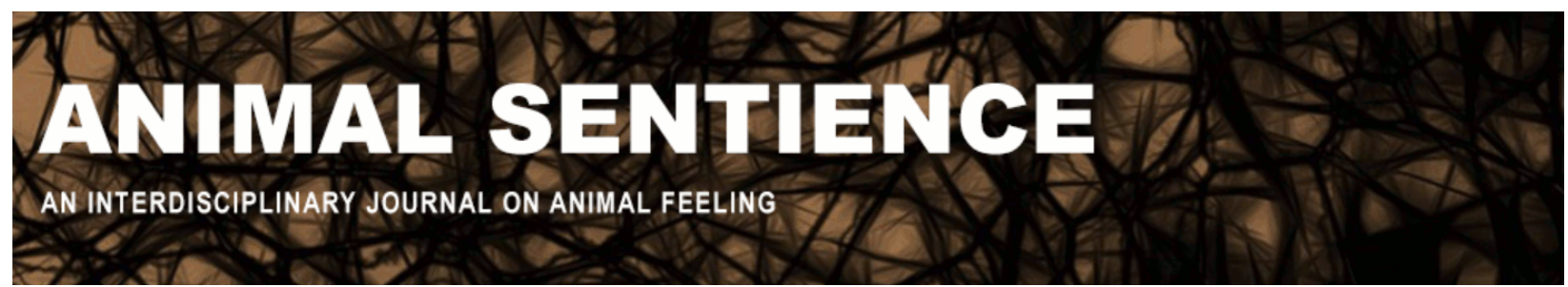

Zentall, Thomas R. (2016) Cognitive dissonance or contrast?. Animal Sentience 12(1)

DOI: $10.51291 / 2377-7478.1111$

Date of submission: 2016-06-11

Date of acceptance: 2016-09-28

(c) 
Call for Commentary: Animal Sentience publishes Open Peer Commentary on all accepted target articles. Target articles are peer-reviewed. Commentaries are editorially reviewed. There are submitted commentaries as well as invited commentaries. Commentaries appear as soon as they have been reviewed, revised and accepted. Target article authors may respond to their commentaries individually or in a joint response to multiple commentaries.

Instructions: http://animalstudiesrepository.org/animsent/guidelines.html

[Editorial note: The following target article discusses the published findings of experiments on captive animals. These involve confinement, manipulation and food-deprivation. Animal Sentience discourages conducting experiments on captive animals and does not publish primary reports of the findings of such experiments. In the context of open peer commentary, however, including criticism of findings from such experiments, secondary references to findings already published elsewhere are unavoidable.]

\title{
Cognitive dissonance or contrast?
}

\author{
Thomas R. Zentall
}

\author{
Department of Psychology, University of Kentucky
}

\begin{abstract}
According to Festinger (1957), cognitive dissonance occurs when one's behavior or belief is inconsistent with another belief and one modifies one of the beliefs in an attempt to reduce the dissonance. In nonhuman animals, we have examined a version of human cognitive dissonance theory called justification of effort, according to which the value of reward following more difficult tasks increases, presumably to justify (to oneself or to others) performing the more difficult task. We have examined the justification of effort effect in animals and found a pattern similar to the one in humans but we propose a simpler underlying mechanism: contrast between the greater effort and the resulting reward that follows. The contrast model predicts that any relatively aversive event will result in a preference for a reward (or for the signal of a reward) that follows. Much evidence supports this model: Signals for reward are preferred if they are preceded by having to make a greater number of responses, encountering a longer delay, or experiencing the absence of food (when food is presented on other trials). Contrast has also been found when the signals are associated with greater rather than less food restriction. We have also found a shift toward the preference of a food location that requires greater effort to obtain. Analogous effects have been found in humans (both children and adults) using similar procedures.
\end{abstract}

Keywords: cognitive dissonance, justification of effort, contrast, pigeons

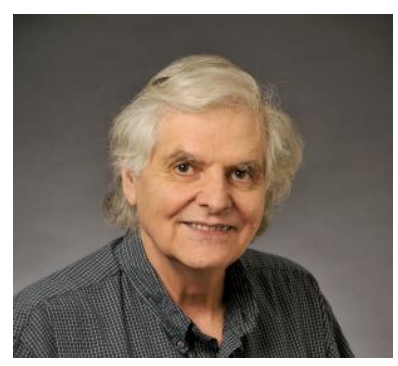

Thomas R. Zentall is Professor of Psychology at the University of Kentucky. His research interests focus on cognitive behaviors in animals including memory strategies, concept learning, and social learning. http://uky.edu/ zentall 


\section{INTRODUCTION}

Cognitive dissonance is a theory of human motivation according to which it is psychologically uncomfortable to hold contradictory cognitions. It has been used to describe the conflict that arises when one's behavior is discrepant with one's beliefs or when two beliefs are discrepant (Festinger, 1957). When dissonance occurs, humans often try to resolve it by changing either their behavior or one of their beliefs. For example, if I smoke cigarettes and I want to be healthy but I understand that smoking is unhealthy, my belief is inconsistent with my behavior and I feel dissonance. To resolve that dissonance, I can stop smoking; or, more likely, I can either ignore how unhealthy smoking is or I can try to convince myself that smoking is not really that unhealthy. Thus, cognitive dissonance has been proposed to account for certain behavior that is not easily accounted for by traditional theories of learning and reinforcement because according to reinforcement theory, given a choice between two alternatives, one should choose the one that gives greater satisfaction. Dissonance should not play a role. Although the resolution of cognitive dissonance may make us feel better, it can be detrimental to our health and can in many cases encourage us to behave inappropriately. The attempt to resolve cognitive dissonance may allow us to hold racist, sexist, speciesist or anti-immigrant beliefs that allow us to discriminate against those who are different from us.

The fact that cognitive dissonance typically occurs because of a discrepancy between behavior and beliefs or between differing beliefs makes it inherently difficult to study in nonverbal species because it would be difficult to assess their beliefs. If animals do have beliefs, does it create dissonance if they are inconsistent? Or is the notion of dissonance a social phenomenon that arises because others value consistency in us and we want to avoid being referred to as hypocritical? If one could find evidence for a cognitive dissonance-like effect in other species, it might not only demonstrate its generality but it might also suggest that a conflict between beliefs is not the primary responsible mechanism.

Justification of effort is a phenomenon subsumed under the larger umbrella of cognitive dissonance and is defined as the tendency to attribute greater value to an outcome that one has put greater effort into acquiring or achieving. In species that do not have language, justification of effort is more amenable to investigation than other examples of cognitive dissonance because relative value can be assessed by looking at choice. Unfortunately, it is difficult to assess the sentience of an animal when it makes a choice or demonstrates a preference, so one must speculate as to the feeling that an animal has when it shows a consistent pattern of choice similar to what we humans might call relief at task completion or task-induced frustration. In justification of effort, the cognitive dissonance is assumed to come about when evaluating the reward relative to the effort required to obtain it. If the effort would be difficult to avoid, the alternative would be to enhance the value of the reward, a more subjective judgment. For example, the child who comes home with a trophy after a season of playing soccer will express greater pride in the prize if it was awarded to the child who showed the greatest improvement in soccer skills (greater effort) than if it had been given to all members of the team for their simple participation (less effort). In the larger context of cognitive dissonance, one may alter the value of the outcome (one's belief) to make it consistent with the behavior that preceded it (Festinger, 1957).

Aronson and Mills (1959) studied the justification of effort experimentally by having participants read aloud as a requirement before listening to a group discussion. Participants 
who had to read aloud embarrassing, sexually explicit material (severe test) judged the following group discussion as more interesting than those who read material that was not sexually explicit (mild test). Aronson and Mills explained their results in terms of cognitive dissonance. They proposed that to justify their behavior (reading embarrassing material aloud) subjects had to increase the value of the group discussion that followed. This finding has important implications for the effect of rites of passage and hazing rituals on group solidarity and loyalty.

\section{THE WITHIN-TRIAL CONTRAST EFFECT}

\subsection{Animal Research}

2.1.1 Manipulated effort. Justification of effort can be studied in nonverbal species by providing an experience obtaining two similar rewards, one requiring greater effort to obtain than the other. Evidence for justification of effort would be obtained if that experience resulted in a preference for the reward that had required greater effort to obtain. To avoid potential problems with the changing value of one reward over another due to satiation or changes in food preference over time we made the actual reward the same on all trials and varied only the color of the stimulus (or conditioned reinforcer) that preceded reinforcement, depending on the response required to obtain the conditioned reinforcer. Thus, the paradigm used by Aronson and Mills (1959) can be adapted for use with animals by training pigeons on some trials to make many pecks for a conditioned reinforcer that predicts food and on other trials to make few pecks for a different conditioned reinforcer that predicts the same food, and then asking them which of the two conditioned reinforcers they prefer (Clement, Feltus, Kaiser, \& Zentall, 2000).

In that research, all trials began with presentation of a white stimulus. On some trials, a single peck was required to turn it off and replace it with, for example, a red hue and a yellow hue, and five pecks to the red hue resulted in reinforcement (see Figure 1). On the remaining trials, 20 pecks to the white stimulus were required to turn it off and replace it with green and blue hues, and five pecks to the green hue resulted in reinforcement. After considerable training, we gave the pigeons a choice between the two stimuli that had been associated with reinforcement (the positive or S+ stimuli).

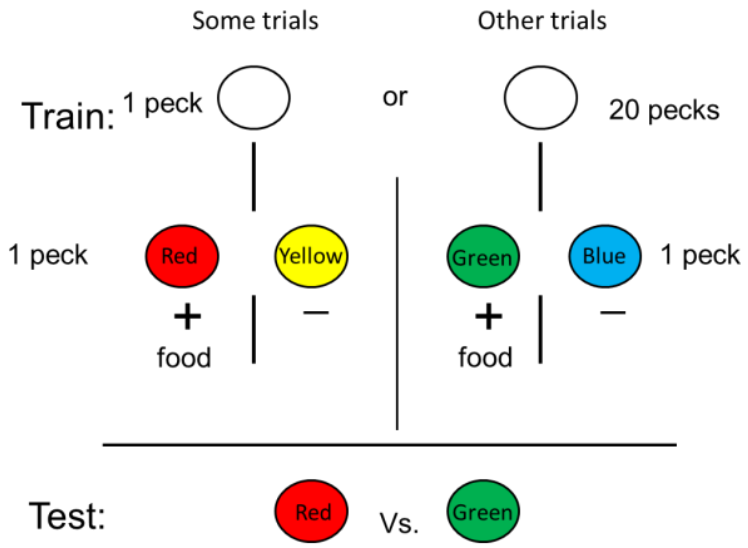

All hues were counterbalanced
Figure 1. Design of Clement et al. (2000) experiment in which on some trials one peck was followed by a choice between red and yellow hues (red was correct, yellow was incorrect), and on other trials 20 pecks were required and were followed by a choice between green and blue hues (green was correct, blue was incorrect). On test trials the pigeons were given a choice between the S+ stimuli from training. They showed a significant preference for the color that required 20 pecks to obtain in training (independent of the number of responses required on test trials). 
According to traditional reinforcement theory (Hull, 1943; Skinner, 1938) the pigeons should have been indifferent to the difference between the hues because they both signaled the same reinforcement. However, if the contiguity between pecks to the white stimulus and presentation of the red and green hues played a role (e.g., Guthrie, 1935) or if the pigeons developed a backward association between the hues and the preceding response (e.g., Spetch, Wilkie, \& Pinel, 1981), then one might expect the pigeons to prefer the red hue that was presented following less effort. Alternatively, if cognitive dissonance theory is correct and justification of effort was involved, the pigeons might prefer the green hue that required 20 pecks to obtain over the red hue that required only one peck, in order to "justify" the additional effort that went into obtaining it. In fact, the pigeons showed a significant preference for the hue that had been preceded by 20 pecks during training (see also Kacelnik \& Marsh, 2002, and for similar, more direct evidence with rats see Lydall, Gilmour, \& Dwyer, 2010).

In this case, one might conclude that the pigeons experienced conflict between their beliefs (the law of least effort) and their behavior (they worked harder on some trials than on others to obtain the same reward), resulting in dissonance; then, to reduce the dissonance, they altered the subjective value of the reward. Alternatively, one can propose a more parsimonious account of the behavior: Whenever judgments of the value of a stimulus are affected not just by their absolute value but by other experienced events, there may be contrast between the initial event and the hue that followed, and the appearance of the green hue after the greater effort may have given the green hue greater value.

Various kinds of contrast have been reported in the literature, including behavioral contrast, incentive contrast, and anticipatory contrast. Because the present contrast is somewhat different from the others, we call it within-trial contrast (Zentall \& Singer, 2007) because it is assumed to occur within a trial between the effort and the reinforcement (or the stimulus that preceded reinforcement). A schematic of this contrast model appears in Figure 2. According to this model, each trial begins with the relative value set at zero. The value of the trial decreases with the effort required and increases with the appearance of the stimulus that signals reinforcement. As the change in value represented by the appearance of that stimulus is greater following the greater effort, it should acquire greater value (see also Meindl, 2012).



Figure 2. Schematic of the within-trial contrast model. FR1 $=$ Fixed Ratio 1 (a single peck). FR20 = Fixed Ratio 20 (20 pecks). $\mathrm{Rf}=$ Reinforcement. 
The strength of the model presented in Figure 2 is in the predictions that it makes. As the nature of the event that precedes the reinforcing event is specified only by its relatively negative value, the model predicts that any relatively negative event should increase the value of the reinforcement (or of the stimulus signaling the reinforcement) that follows.

2.1.2 Manipulated delay. DiGian, Friedrich, and Zentall (2004) manipulated the delay between the initial link stimulus and the signal for reinforcement. Pigeons started each trial by pecking an initial stimulus that signaled whether it would be followed by a relatively long delay or not. If the initial stimulus signaled no delay, it was immediately followed by a simple simultaneous discrimination (e.g., red+, yellow-) and the choice of red was reinforced. If the initial stimulus signaled a delay, it was followed by a 6-s delay and then a different simple simultaneous discrimination (e.g., green+, blue-), and the choice of green was reinforced. On test trials a significant preference was found for the S+ stimulus that followed the 6-s delay.

2.1.3 Manipulated absence of food. Another relatively negative event is the absence of food when on other trials food would be present. To test the prediction that the absence of food can serve as a relatively negative event, Friedrich, Clement, and Zentall (2005) signaled that a response to the initial stimulus would be followed by food and a simultaneous discrimination or by the absence of food and a different simultaneous discrimination. Consistent with the contrast model, on test trials, the pigeons showed a preference for the S+ stimulus that followed the absence of reinforcement.

2.1.4 The location of food as the discriminated event. When considering the evolutionary basis for a phenomenon, it is often instructive to consider the adaptive value such behavior might have had in nature. One possibility is that when food is scarce, if food that is difficult to obtain (a relatively negative condition) has added value, it might encourage the animal to continue to search longer. What if food was difficult to obtain because the animal had to travel longer or work harder to obtain it? To test this hypothesis, Friedrich and Zentall (2004) trained pigeons to peck a yellow stimulus once on half of the trials to obtain food at one feeder and 30 times on the remaining trials to obtain food at a different feeder. Following this training, when the pigeons were given a choice between the two feeders, Friedrich and Zentall found a reliable shift in feeder preference in the direction of the 30-peck feeder. Once again, the relatively aversive event resulted in a shift in preference, in this case towards the location of the food reward.

2.1.5 The state of the organism as the discriminated event. Further evidence of the generality of this contrast effect comes from research by Kacelnik and his collaborators (Aw, Holbrook, Burt de Perera, \& Kacelnik, 2009; Aw, Vasconcelos, \& Kacelnik, 2011; Marsh, Schuck-Paim, \& Kacelnik, 2004; Pompilio \& Kacelnik, 2005; Pompilio, Kacelnik, \& Behmer, 2006). Marsh et al. (2004), for example, extended the predictions of the contrast model by manipulating the degree of food deprivation of starlings. According to the contrast account, increased food deprivation should be associated with a relatively aversive state. Thus, one color was associated with food under conditions of mild food deprivation and a different color was associated with food under conditions of greater food deprivation. Marsh et al. found that the starlings preferred the color that predicted food when they were more food 
deprived than when they were less food deprived, and they preferred that color whether they were more or less food deprived on test days. A very similar effect was reported in research with pigeons (Fox \& Kyonka, 2014; Vasconcelos \& Urcuioli, 2008), fish (Aw, Holbrook, de Perera, \& Kacelnik, 2009), and even locusts (Pompilio, Kacelnik, \& Behmer, 2006).

\subsection{Similar Results Found with Humans}

If this contrast effect can serve as a model for justification-of-effort effects that have been found in humans, one should be able to find similar contrast effects in humans using these procedures. When Alessandri, Darcheville, and Zentall (2008) tested 7- to 8-year-old children using the Clement et al. (2000) procedure with computer mouse clicks in place of effort and shapes instead of colors as the discriminative stimuli, they found a similar preference for the shapes that followed the greater number of mouse clicks. Further support for the theory was reported by Klein, Bhatt, and Zentall (2005), who tested adults on a similar version of the task and found similar results. Furthermore, after the experiment the subjects generally reported that they were unaware of the relation between the effort required and the correct shape that followed. These results suggest that awareness of the relation between effort and reward is not needed to produce the contrast found. Finally, when Alessandri, Darcheville, Delevoye-Turrell, and Zentall (2008) attempted to control for the differences in duration between high and low effort trials (see Fantino \& Abarca, 1985) by using differential pressure on a transducer as the differential effort manipulation, they found that S+ stimuli that followed greater effort were preferred over those that followed less effort.

\section{CONTRAST RESULTING FROM A POTENTIALLY AVERSIVE EVENT}

To what extent might the effort itself, rather than contrast, account for the preferences found? For example, is it possible that relatively negative events result in arousal and arousal leads to better learning of the stimuli that follow? Clement and Zentall (2002) asked if one could obtain a preference for the discriminative stimuli that followed a signal that high effort might be - but was not actually - required on that trial. More specifically, on half the training trials, pigeons were initially presented with a vertical line which signaled on half the trials that low effort (single peck; FR1) would be required for reinforcement (see Figure 3). On the remaining vertical-line trials, pecking the vertical line replaced it with a simultaneous discrimination S+FR1/S-FR1 (the discrimination that on other trials produced reinforcement following a single peck) and the choice of the S+FR1 was reinforced. On the remaining training trials, pigeons were presented with a horizontal line that signaled on half of the trials that greater effort (30 pecks, FR30) would be required. On the remaining horizontal-line trials, pecking the horizontal line replaced it with a different simultaneous discrimination S+FR30/SFR30 and the choice of the S+FR30 was reinforced.

On test trials, when the pigeons were given a choice between the S+FR1 and the S+FR30, they showed a significant preference for the S+FR30. Thus, the line orientation that was sometimes followed by a greater response requirement was sufficient to produce a preference for the S+ stimulus that followed it on other trials. These results extend the findings of the within-trial contrast research and show that the anticipation of a possible aversive event is sufficient to produce a within-trial contrast effect. Furthermore, differential 
arousal produced by the actual effort just before the simultaneous discrimination is not required to produce the contrast effect.

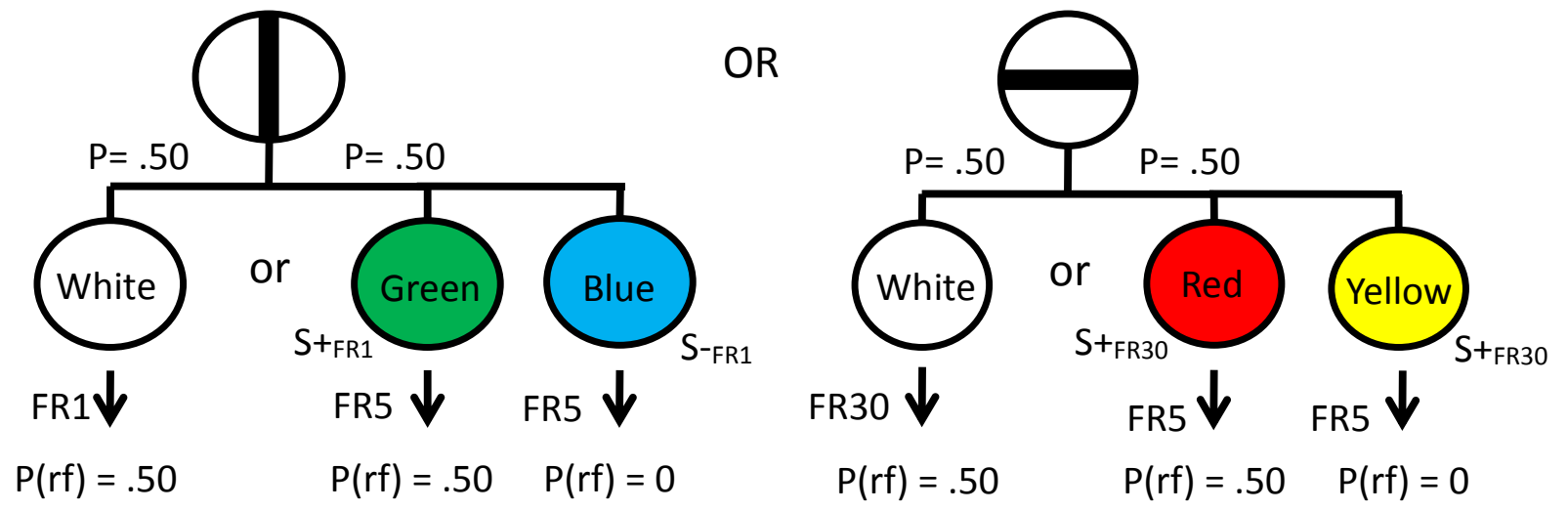

Figure 3. Design of Clement and Zentall (2002) Experiment 1. Pigeons received the vertical line on half the trials and the horizontal line on the remaining trials. Pecking the vertical line resulted in an easy single peck to the white key for food ( $50 \%$ of the time for $50 \%$ reinforcement) or a bit harder 5 pecks to the green key on the remaining trials for food (50\% of the time; pecks to blue were never reinforced). Pecking the horizontal line resulted in a more difficult 30 pecks to the white key for food (50\% of the time for $50 \%$ reinforcement) or an easier 5 pecks to the red key on the remaining trials for food $50 \%$ of the time; pecks to yellow were never reinforced). On test trials when the pigeons were given a choice between the green and red stimuli, they preferred the red one, the stimulus that represented an outcome better than the white FR30 (30 pecks), whereas the green stimulus represented an outcome worse than the white FR1 (a single peck). S+FR1 = The positive (reinforced) stimulus that on other vertical line trials resulted in an FR1 pecking requirement. S-FR1 $=$ The negative (nonreinforced) stimulus that on other vertical line trials resulted in an FR1 pecking requirement. S+FR30 $=$ The positive (reinforced) stimulus that on other horizontal line trials resulted in an FR30 pecking requirement. S-FR30 $=$ The negative (nonreinforced) stimulus that on other horizontal line trials resulted in an FR30 pecking requirement. FR5 $=5$ pecks. $\mathrm{P}(\mathrm{rf})=$ probability of reinforcement.

\section{OTHER FORMS OF DISSONANCE REDUCTION}

\subsection{Out of Sight, Out of Mind}

Although the justification-of-effort phenomenon is particularly amenable to translation to a task that can be studied in non-human animals, it shows up as a bias rather than as dissonance that must be resolved. Many examples of cognitive dissonance arise from the choice between a small immediate outcome and a larger delayed or less probable outcome. Such a choice is made difficult because the value of the delayed or less probable reward is reduced relative to that of the immediate reward (i.e., delayed and less probable rewards are discounted). For example, cigarette smokers may value both the immediacy of smoking a cigarette and the delayed prospects of better health for not smoking. Considering these opposing alternatives is likely to produce dissonance, which can be reduced by rationalization. "Many people smoke and stay healthy." That is, one can deny the negative consequences of the choice to smoke. Alternatively, one may choose to disregard the health consequences of smoking because deliberate ignorance allows one to avoid cognitive dissonance (Hertwig \& Engel, 2016).

Interestingly, because the value of the immediate and delayed options typically changes over time, instead of denying the long-term negative consequences of smoking, one 
may try to find a way to compensate for the increasing value of the immediate reinforcement of smoking as the urge becomes greater. One way to accomplish this is by making a commitment to counter the attraction to the small immediate reward at a time when the immediate value of smoking is not so strong. For example, one may arrange to see a behavioral therapist (at some expense) who offers a device that provides shocks for smoking. Given that one could, in principle, decide to forgo cigarettes without such an intervention, one has instead chosen to spend money on a therapist who provides the opportunity to selfadminister aversive shocks. This solution would appear to be a complex cognitive decision difficult to explain with behavioral principles and unlikely to be demonstrated by non-human animals. Because animals are non-verbal, it would be difficult to assess their beliefs except by way of their behavior.

Pigeons may nevertheless show behavior somewhat like that of the smoker motivated to stop smoking when the pigeons are faced with a difficult schedule of reinforcement. For example, differential reinforcement of low rates of responding (DRL schedule) reinforces responding but only if the response is preceded by a specified period without a response. Schwartz and Williams (1971) trained pigeons to wait at least $6 \mathrm{~s}$ before pecking a green light, after which the first response was reinforced. However, any peck before $6 \mathrm{~s}$ had elapsed terminated the trial. Under these conditions the pigeons performed poorly, receiving reinforcement on only about $4 \%$ of the trials. Schwartz and Williams then provided the pigeons with a nearby blue light (simultaneously with the green light) to which pecking had no consequence. Not only did the pigeons begin to peck the blue light but also pecking it allowed them to avoid pecking the green light; now the pigeons received over $70 \%$ of the possible reinforcements. How is this relevant to the complex decision-making presumed to occur when humans seek aversion therapy? In principle, the pigeon could choose to refrain from pecking the green stimulus but it soon learns that waiting is very difficult. One can think of pecking the blue light as a cost that removes the pigeons from the "temptation" to peck the green light, thereby facilitating successful learning on this task.

Alternatively, one could interpret the results of this pigeon experiment in terms of cognitive dissonance: there was a conflict between pecking early and waiting that caused dissonance on the assumption that the pigeon would have preferred getting fed on all trials. However, only when the pigeon was induced to refrain from pecking the green light by providing it with another light to peck was it able to obtain the majority of available reinforcements. Just as stopping smoking should not have required that the smoker pay a therapist to provide a shocking device, so too the DRL schedule did not require the pigeon to peck the blue light. However, the blue light allowed the pigeon to avoid the temptation of pecking the green light and thus to avoid the dissonance resulting from its negative consequences (in this case with the blue light, the green stimulus was "out of sight, out of mind").

\subsection{Spreading of Alternatives and Public Choice}

Another form of cognitive dissonance involves the value added to an option once it has been adopted (or the reduction of value for options not adopted) especially when the decision is a difficult one (Harmon-Jones \& Mills, 1999). This phenomenon, called the spreading of alternatives, presumably occurs because after selection minor changes in the value of the options could lead to dissonance (an option not adopted might now seem better 
or the option adopted might now seem worse). Giving the already chosen option greater value following choice would resolve the potential dissonance.

A similar phenomenon, sometimes referred to as dissonance produced by public choice, occurs when people vote for one of two candidates, especially if it is a difficult choice (Beasley \& Joslyn, 2001). To reduce the potential dissonance that may come from learning bad things about the chosen candidate or good things about the unchosen candidate, those who have voted in a recent presidential election show greater polarization in their ratings of the two candidates immediately after the election than immediately before (as compared to those who do not report having voted). That is, those who voted for a candidate tend to have a more favorable opinion of that candidate and a less favorable opinion of the other candidate than before the election.

Egan, Santos, and Bloom (2007) tested for a reduction in preference for an unchosen alternative in a non-verbal species: capuchin monkeys. Subjects were given a choice between two equally preferred rewards. They were then given a choice between the unchosen alternative and an alternative that was originally just as attractive as both of the original alternatives. The monkeys preferred the novel alterative over the unchosen original alternative. That is, although the subjects should have been indifferent between the two alternatives, they apparently valued the initially unchosen alternative less.

Although one could conclude from this experiment that monkeys too tend to reject the initially unchosen alternative in order to reduce the possibility of dissonance resulting from its initial rejection, Chen and Risen (2009) argue that in the case of the Egan, Santos, and Bloom (2007) experiment, the original determination of the indifference among the three alternatives was not likely to be correct. That determination was based on the nonsignificant difference in the latency to retrieve each of the three rewards. Yet not only is non-significance different from indifference but also latency of response may not always be consistent with choice (see Williams, 1992). Furthermore, Chen (2008) more specifically accounts for the spreading-of-alternatives effect by simply including the information provided by the initial choice in the later choice. That is, subjects weigh information to make their initial choice. When they make their later choice or evaluation, they include the fact of their initial choice which should make their later choice more polarized. To my knowledge there is no published animal research that has tested this.

\section{IMPLICATIONS OF COGNITIVE DISSONANCE RESEARCH WITH ANIMALS}

If the contrast hypothesis is correct, then it provides an alternative account of the justification-of-effort effect, which has been attributed to an attempt to resolve the dissonance from the conflict between beliefs and behavior or between two different beliefs. Contrast suggests that the basis for the justification-of-effort effect may be simpler. Whether contrast can account for all human cases of cognitive dissonance is not clear but it may be the underlying basis for this cognitive dissonance effect. It is also important to ask whether to experience cognitive dissonance is it necessary for one to have conflicting beliefs or even beliefs at all? If so, is it necessary to experience dissonance or tension as a result of that conflict? And if so, is the resulting behavior an attempt to resolve that tension? The research presented here suggests that there may be an alternative account, not only for pigeons but also for humans, because the preference for the outcome that follows the relatively negative initial event occurs under conditions that would not appear to require justification for one's 
preference (Alessandri, Darcheville, Delevoye-Turrell, \& Zentall, 2008; Alessandri, Darcheville, \& Zentall, 2008; Klein, Bhatt, \& Zentall, 2005).

It should be noted that the contrast account of justification of effort does not deny the role of emotion or sentience (felt state) on the part of the animal; in fact, several investigators have suggested what emotional state it might be. Crespi (1942), for example, has described contrast in animals in terms of elation when the value of a reward is greater than expected (positive contrast) and depression when it is worse than expected (negative contrast). And with the procedures described here, the emotion experienced upon encountering the more negative event is likely to be frustration - an emotion proposed by Amsel (1958). The contrast account does imply, however, that this form of contrast need not depend on the social construct of the need for consistency between one's beliefs or on the implied social mechanism, the avoidance of hypocrisy. That is, the need to be consistent may be a human construct that overlays the underlying contrast and serves to motivate and then rationalize the resolution of the dissonance caused by the inconsistency.

The contrast account may also have implications for rational decision-making. Justification of effort implies the rationalization of one's behavior. "Although I generally believe $\mathrm{X}$, in this case I was justified in doing Y." Contrast, however, merely implies there is a preferred outcome or bias due to what came before it. Because we are social animals, we may experience contrast and we may also feel an obligation to justify our behavior (to ourselves as well as to others). However, the obligation to justify one's actions may arise from the bias: the added value of the outcome produced by contrast. That is, contrast may provide an added value for all organisms but it is very likely to be only humans who need to justify it to themselves or to others.

If the cognitive dissonance results from contrast, it suggests that the bias is automatic and justification comes after the fact. Thus, if one wants to avoid the bias, it may not be sufficient to avoid justifying the belief or the resulting behavior because the contrast-induced bias may remain. Instead, one may need to recognize its automatic nature. If one wants to make a rational choice, one should attempt to discount the contrast produced by the prior effort. For example, if one is interested in joining a group, although the cost of initiation may be a factor in making that choice, one should try to avoid including that cost again in deciding on the value of the group.

It should also be noted that although contrast may provide an alternative, more parsimonious, account of certain complex social-psychological phenomena, the presence of contrast implies a form of relational learning that cannot be accounted for by means of traditional behavioral theories and thus needs to be explained in its own right (see e.g., Flaherty, 1996).

Other forms of cognitive dissonance may arise from the choice of immediate reinforcement (e.g., smoking a cigarette) and the conflict resulting from the delayed probabilistic negative consequences of that choice (e.g., poor health). Often denial is the mechanism that is used to deal with the dissonance. Alternatively, however, the conflict may be resolved by taking measures to make it less likely to smoke and more likely to obtain the delayed reinforcement of better health (e.g., aversion therapy). Interestingly, similar effects can be found in pigeons when they choose to expend effort to avoid the impulse to respond too early (Schwartz \& Williams, 1971). 


\section{CONCLUSIONS}

The results of the experiments with animals presented here suggest that it would be more parsimonious to explain the findings in terms of within-trial contrast rather than cognitive dissonance or justification of effort. But they also raise the possibility that similar contrast effects may play a role when analogous results are found in research with humans. Imagine, for example, the results of the classic experiment by Festinger and Carlsmith (1959). Subjects took part in a monotonous repetitive task involving turning pegs in holes. They were then asked to describe the task as "interesting" to a subject in the next room and were paid either $\$ 1$ or $\$ 20$ before doing so. But before engaging in their deceitful assignment, they were asked to rate the peg-turning task they had just completed. Surprisingly, those subjects that had been paid $\$ 1$ rated the task as more interesting than those subjects that had been paid $\$ 20$. Festinger and Carlsmith interpreted their findings in terms of cognitive dissonance. Those who were paid $\$ 20$ could justify to themselves what they were going to do because of the large payment, whereas those who were paid only $\$ 1$ could not. For those who were paid only $\$ 1$, the theory suggests that the only way they could justify to themselves what they had agreed to do was to modify their belief in the nature of the preceding monotonous task.

According to the model presented in Figure 2, however, the peg-turning task would put the subjects in a somewhat negative state, whereas the promise of payment would have had a positive effect on their state and the larger payment would have had a still larger positive effect. When the subjects were then asked to rate the peg-turning task, they would have viewed the task retrospectively from a higher $(\$ 20)$ or somewhat lower $(\$ 1)$ positive state. Relative to the higher positive state, the peg-turning task would have appeared to have more negative value than the lower positive state. Thus, there would have been a smaller judgment of task aversiveness (i.e., less contrast) following the smaller payment.

A similar interpretation would be applicable to a range of results including the justification-of-effort effect (Aronson \& Mills, 1959). One could interpret the relief one feels at the completion of a difficult task and the reward that follows as a relatively large change in hedonic state from negative to positive. The more negative the state one experiences during the difficult task, the greater should be the relative change in state upon its completion.

The hypothesis that contrast may be involved in what appear to be complex social phenomena does not mean that social influence is not also involved. Cognitive dissonance or justification of effort involving discrepancies between behavior and beliefs may also contribute to the paradoxical behavior demonstrated. The animal research reported here suggests, however, that these more complex social phenomena may be based on simpler less cognitive processes involving mechanisms common to many species. That is, these complex processes may overlay the simpler contrast effects on which they are based. A goal of future research will be to develop procedures to distinguish between contrast and more cognitive accounts and to determine the degree to which belief-based theories are needed to account for the cognitive dissonance effects found. 
Call for Commentary: Animal Sentience publishes Open Peer Commentary on all accepted target articles. Target articles are peer-reviewed. Commentaries are editorially reviewed. There are submitted commentaries as well as invited commentaries. Commentaries appear as soon as they have been reviewed, revised and accepted. Target article authors may respond to their commentaries individually or in a joint response to multiple commentaries. Instructions: http://animalstudiesrepository.org/animsent/guidelines.html

\section{References}

Alessandri, J., Darcheville, J.-C., \& Zentall, T. R. (2008). Cognitive dissonance in children: Justification of effort or contrast? Psychonomic Bulletin \& Review, 15, 673-677.

Alessandri, J., Darcheville, J.-C., Delevoye-Turrell, Y., \& Zentall, T. R. (2008). Preference for rewards that follow greater effort and greater delay. Learning \& Behavior, 36, 352-358.

Amsel, A. (1958). The role of frustrative nonreward in noncontinuous reward situations. Psychological Bulletin, 55, 102-119.

Arantes, J., \& Grace, R. C. (2008). Failure to obtain value enhancement by within-trial contrast in simultaneous and successive discriminations. Learning \& Behavior, 36, 1-11.

Aronson, E., \& Mills, J. (1959). The effect of severity of initiation on liking for a group. Journal of Abnormal and Social Psychology, 59, 177-181.

Aw, J. M., Holbrook, R. I., Burt de Perera, T., \& Kacelnik, A. (2009) State-dependent valuation learning in fish: Banded tetras prefer stimuli associated with greater past deprivation. Behavioural Processes, 81, 333-336.

Aw, J. M., Vasconcelos, M., \& Kacelnik, A. (2011). How costs affect preferences: Experiments on state-dependence, hedonic state and within-trial contrast in starlings. Animal Behaviour, 81, 1117-1128.

Beasley, R. K., \& Joslyn, M. R. (2001). Cognitive dissonance and post-decision attitude change in six presidential elections. Political Psychology, 22, 521-540.

Clement, T. S., \& Zentall, T. R. (2002). Second-order contrast based on the expectation of effort and reinforcement. Journal of Experiment Psychology: Animal Behavior Processes, 28, 64-74.

Clement, T. S., Feltus, J., Kaiser, D. H., \& Zentall, T. R. (2000). 'Work ethic' in pigeons: Reward value is directly related to the effort or time required to obtain the reward. Psychonomic Bulletin \& Review, 7, 100-106.

Crespi, L. P. (1942). Quantitative variation of incentive and performance in the white rat. American Journal of Psychology, 55, 467-517.

DiGian, K. A., Friedrich, A. M., \& Zentall, T. R. (2004). Discriminative stimuli that follow a delay have added value for pigeons. Psychonomic Bulletin \& Review, 11, 889-895.

Fantino, E., \& Abarca, N. (1985). Choice, optimal foraging, and the delay-reduction hypothesis. Behavioral and Brain Sciences, 8, 315-330.

Festinger, L. (1957). A theory of cognitive dissonance. Stanford, CA: Stanford University Press.

Festinger L., \& Carlsmith, J. M. (1959). Cognitive consequences of forced compliance. Journal of Abnormal and Social Psychology, 58, 203-210. 
Flaherty, C. F. (1996). Incentive relativity. Cambridge, MA: Cambridge University Press.

Fox, A. E., \& Kyonka, E. G. E. (2014). Choice and timing in pigeons under differing levels of food deprivation. Behavioral Processes, 106, 82-90.

Friedrich, A. M., \& Zentall, T. R. (2004). Pigeons shift their preference toward locations of food that take more effort to obtain. Behavioural Processes, 67, 405-415.

Friedrich, A. M., Clement, T. S., \& Zentall, T. R. (2005). Discriminative stimuli that follow the absence of reinforcement are preferred by pigeons over those that follow reinforcement. Learning \& Behavior, 33, 337-342.

Guthrie, E. R. (1935). The psychology of learning. New York: Harper.

Harmon-Jones, E., \& Mills, J. (1999). Cognitive dissonance: Progress on a pivotal theory in social psychology. Washington, DC: American Psychological Association.

Hertwig, R., \& Engel, C. (2016). Homo ignorans: Deliberately choosing not to know. Perspectives on Psychological Science, 11, 359-372.

Hull, C. L. (1943). Principles of behavior. New York: Appleton-Century-Crofts.

Kacelnik, A., \& Marsh, B. (2002). Cost can increase preference in starlings. Animal Behaviour, 63, 245-250.

Klein, E. D., Bhatt, R. S., \& Zentall, T. R. (2005). Contrast and the justification of effort. Psychonomic Bulletin \& Review, 12, 335-339.

Lawrence, D. H., \& Festinger, L. (1962). Deterrents and reinforcement: The psychology of insufficient reward. Stanford, CA: Stanford University Press.

Lydall, E. S., Gilmour, D., \& Dwyer, G. M. (2010). Rats place greater value on rewards produced by high effort: An animal analogue of the "effort justification" effect. Journal of Experimental Social Psychology, 46, 1134-1137.

Marsh, B., \& Kacelnik, A. (2002). Framing effects and risky decisions in starlings. Proceedings of the National Academy of Sciences, 99, 3352-3355.

Marsh, B., Schuck-Paim, C., \& Kacelnik, A. (2004). Energetic state during learning affects foraging choices in starlings. Behavioral Ecology, 15, 396-399.

Meindl, J. N. (2012). Understanding preference shifts: A review an alternative explanation of within-trial contrast and state-dependent valuation. Behavior Analysis, 35, 179-195.

Pompilio, L., \& Kacelnik, A. (2005). State-dependent learning and suboptimal choice: When starlings prefer long over short delays to food. Animal Behaviour, 70, 571-578.

Pompilio, L., Kacelnik, A., \& Behmer, S. T. (2006). State-dependent learned valuation drives choice in an invertebrate. Science, 311(5767), 1613-1615.

Schwartz, B., \& Williams, D. R. (1971). Discrete-trials spaced responding in the pigeon: The dependence of efficient performance on the availability of a stimulus for collateral pecking. Journal of the Experimental Analysis of Behavior, 16, 155-160.

Singer, R. A., Berry, L. M., \& Zentall, T. R. (2007). Preference for a stimulus that follows a relatively aversive event: Contrast or delay reduction? Journal of the Experimental Analysis of Behavior, 87, 275-285.

Skinner, B. F. (1938). The behavior of organisms. New York: Appleton-Century-Crofts.

Spetch, M. L., Wilkie, D. M., \& Pinel, J. P. J. (1981). Backward conditioning: A reevaluation of the empirical evidence. Psychological Bulletin, 89, 163-175.

Vasconcelos, M., \& Urcuioli, P. J. (2008). Deprivation level and choice in pigeons: A test of within-trial contrast. Learning \& Behavior, 36, 12-18.

Vasconcelos, M., Urcuioli, P. J., \& Lionello-DeNolf, K. M. (2007). Failure to replicate the workethic effect. Journal of the Experimental Analysis of Behavior, 87, 383-399. 
Williams, B. A. (1992). Inverse relations between preference and contrast. Journal of the Experimental Analysis of Behavior, 58, 303-312.

Zentall, T. R., \& Singer, R. A. (2007). Within-trial contrast: Pigeons prefer conditioned reinforcers that follow a relatively more rather than less aversive event. Journal of the Experimental Analysis of Behavior, 88, 131-149. 


\section{“I Am Not an Animal!" \\ The Signature Cry of Our Species



ur fellow animals and the Earth are under increasing threat from human activities. Anthropogenic climate change, habitat destruction and an unfolding mass extinction all beg the key question: Why are we incapable of changing our behavior?

At this unique two-day symposium, we look at how our behavior is driven psychologically by the need to see ourselves as separate from and superior to the rest of nature. And we ask why we need to keep telling ourselves, through our actions and belief systems, that "I am not an animal!"

We explore this exceptionalist view of ourselves with leaders in the fields of psychology, ecology, ethics, philosophy, law and advocacy. And we discuss how we can apply their insights to environmental and animal protection efforts.

WHEN February 24-25, 2017

\section{WHERE}

Emory Conference

Penter

1615 Clifton Road ME, Atlanta, GA 30329

Organized by Lori Marino, John Schacke, MichaeIMountain

REGISTRATION \& FULL INFORMATION www.not-an-animal.org

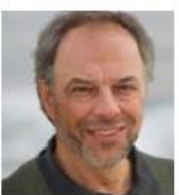

The State of Planet Earth Today

Keynote address: Author and conservationist Carl Safina takes stock of what scientists are calling the Sixth Mass Extinction and where it may be heading.

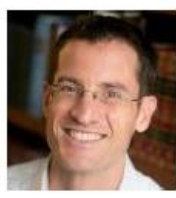

Our Planet \& Ourselves in

History and Mythology

Bioethicist Jonathan Crane talks

about the stories we've told

ourselves over the millennia about our origins and our relationship to the other animals.

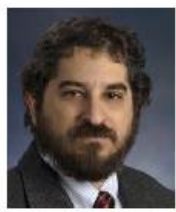

How We "View" Other

Animals

Randy Malamud, Prof. of English, Georgia State University, author of Reading Zoos, discusses the psychology of keeping animals in zoos, aquariums and circuses.

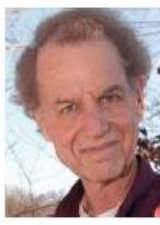

Some We Love, Some We Hate, Some We Eat

Hal Herzog, author, Emeritus Prof. of Psychology, Western Carolina University, explores the confusing relationships we have with different kinds of animals.

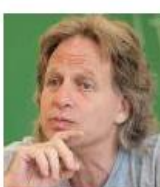

The Worm at the Core Sheldon Solomon, author and Prof. of Psychology, Skidmore College, explains how our civilization and culture act as a defense against the anxiety we fee about our mortal, animal nature.

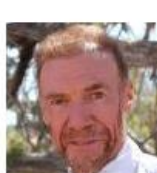

"I Am Not an Animal!"

Michael Mountain, former President of Best Friends Animal Society, discusses how advocacy efforts are hobbled by people's denial (often-subconscious) that we humans are animals, too

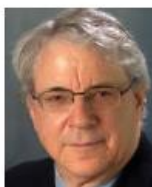

Nonhuman Animals as Legal Persons

Steven Wise, President of the Nonhuman Rights Project, explains how the legal system treats nonhuman animals as "things", as it once did with slaves, women and children.

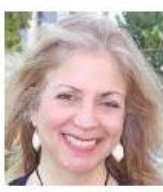

Someone, Not Something Lori Marino, Director of The Kimmela Center for Animal Advocacy, talks about how we are coming to see other animals as "someone" rather than "something" - as individuals in their own right.

Group Discussion

What do these insights indicate for environmental and animal protection efforts?

\section{SCHEDULE \& DETAILS} www.not-an-animal.org 
Animal Sentience 2016.142: Zentall on Cognitive Dissonance 